\title{
$\alpha$-melanocyte stimulating hormone modulates the central acyl ghrelin-induced stimulation of feeding, gastrointestinal motility, and colonic secretion
}

This article was published in the following Dove Press journal:

Drug Design, Development and Therapy

16 August 2017

Number of times this article has been viewed

\author{
Hsien-Hao Huang ${ }^{1,2}$ \\ Liang-Yu Chen ${ }^{3,4}$ \\ Ming-Luen Doong ${ }^{5}$ \\ Shi-Chuan Chang ${ }^{6,7}$ \\ Chih-Yen Chen ${ }^{8-10}$
}

'Institute of Clinical Medicine, National Yang-Ming University of Medicine, ${ }^{2}$ Department of

Emergency Medicine, Taipei Veterans General Hospital, ${ }^{3}$ Aging and Health Research Center, National Yang-Ming University, ${ }^{4}$ Center for Geriatrics and Gerontology, Taipei Veterans General Hospital, ${ }^{5}$ Institute of Physiology, National Yang-Ming University School of Medicine, ${ }^{6}$ Institute of Emergency and Critical Medicine, National YangMing University School of Medicine, ${ }^{7}$ Department of Chest Medicine, Taipei Veterans General Hospital, ${ }^{8}$ Division of Gastroenterology and Hepatology, Department of Medicine, Taipei Veterans General Hospital,

${ }^{9}$ Faculty of Medicine, National YangMing University School of Medicine, Taipei, ${ }^{10}$ Taiwan Association for the Study of Small Intestinal Diseases, Guishan, Taiwan
Correspondence: Chih-Yen Chen Division of Gastroenterology and Hepatology, Taipei Veterans General Hospital, 20I, Sec. 2, Shih-Pai Road, Taipei II2, Taiwan

Tel +886 22 87| 2 I 2 I ext 3763

Fax +886 $22871 \quad 1058$

Email chency@vghtpe.gov.tw
Background: Acyl ghrelin-induced intake depends on hypothalamic neuropeptide $\mathrm{Y}$ and agouti-related protein (AgRP) neurotransmitters. Intracerebroventricular (ICV) injection of AgRP increases feeding through competitive antagonism at melanocortin receptors. ICV administration of $\alpha$-melanocyte stimulating hormone ( $\alpha-\mathrm{MSH})$, a natural antagonist of AgRP, may modulate the acyl ghrelin-induced orexigenic effect.

Objective: This study aimed to investigate the modulating effect of $\alpha-\mathrm{MSH}$ on the central acyl ghrelin-induced food intake, gastrointestinal motility, and colonic secretion in rats.

Methods and procedures: We examined the effects of $\alpha$-MSH and acyl ghrelin on food intake, gastric emptying, small intestinal transit, colonic motility, and secretion in conscious rats with a chronic implant of ICV catheters.

Results: ICV injection of $O$ - $n$-octanoylated ghrelin $(0.1 \mathrm{nmol} / \mathrm{rat})$ significantly increased the cumulative food intake up to $8 \mathrm{~h}(P<0.01)$, enhanced non-nutrient semi-liquid gastric emptying $(P<0.001)$, increased the geometric center and running percentage of small intestinal transit $(P<0.001)$, accelerated colonic transit time $(P<0.05)$, and increased fecal pellet output $(P<0.01)$ and total fecal weight $(P<0.01)$. Pretreatment with ICV injection of $\alpha$-MSH $(1.0$ and $2.0 \mathrm{nmol} / \mathrm{rat}$ ) attenuated the acyl ghrelin-induced hyperphagic effect, fecal pellet output, and total fecal weight, while higher dose of $\alpha-\mathrm{MSH}(2.0 \mathrm{nmol} / \mathrm{rat})$ attenuated the increase in the geometric center of small intestinal transit $(P<0.01)$. However, neither dose of $\alpha$-MSH altered acyl ghrelin-stimulated gastroprokinetic effect, increase in the running percentage of small intestinal transit, nor accelerated colonic transit time.

Conclusion: $\alpha-\mathrm{MSH}$ is involved in central acyl ghrelin-elicited feeding, small intestinal transit, fecal pellet output, and fecal weight. $\alpha$-MSH does not affect central acyl ghrelin-induced acceleration of gastric emptying and colonic transit time in rats.

Keywords: acyl ghrelin, colon transit time, fecal pellet output, food intake, gastric emptying, intracerebroventricular, small intestinal transit, $\alpha$-melanocyte stimulating hormone

\section{Introduction}

Acyl ghrelin, a 28-amino acid peptide, was first isolated from the stomach and is expressed in the intestine, pancreas, lungs, heart, adipose tissue, and hypothalamic regions (including the arcuate nucleus and pituitary). ${ }^{1,2}$ Acyl ghrelin is also involved in modulating cardiovascular apoptosis, ${ }^{3}$ reproduction, ${ }^{4}$ bone marrow adipogenesis,${ }^{5}$ and proliferation of pancreatic $\beta$-cells and human cells. ${ }^{6}$ It is the first known endogenous ligand acting across the blood-brain barrier $^{7}$ on growth hormone $(\mathrm{GH})$ secretagogue receptors (GHS-R) and ghrelin-immunoreactive neurons in the hypothalamic arcuate nucleus. ${ }^{1}$ In addition to stimulating the release of $\mathrm{GH}$, acyl ghrelin activates the release 
of neuropeptide Y (NPY) and agouti-related protein (AgRP) because GHS-R are present on almost all NPY/AgRP neurons in arcuate nuclei. ${ }^{8,9}$ Acyl ghrelin induces the expression of NPY and AgRP mRNA in the hypothalamus and stimulates food intake and body weight gain. ${ }^{10-12}$ At present, acyl ghrelin is the only known peripheral signal that elicits food intake in humans. ${ }^{13,14}$

The effects of acyl ghrelin on food intake depend on hypothalamic NPY and AgRP neurotransmitters, two potent orexigenic peptides. ${ }^{15,16}$ Chemical ablation of GH, NPY, and AgRP with monosodium glutamate in the hypothalamic arcuate nucleus attenuates increases of ghrelin-induced food intake. ${ }^{17}$ In $\mathrm{AgRP}^{--} \mathrm{NPY}^{-/-}$double-knockout mice, peripheral acyl ghrelin fails to elicit hyperphagia. ${ }^{16}$ Ghrelin-induced increase in foraging and food intake is not always attenuated by the NPY Y1 antagonist, 1229U91. ${ }^{18} \mathrm{NPY}^{-/-}$singleknockout mice show severely compromised ghrelin-induced food intake, and this effect can be partially compensated by AgRP activity. ${ }^{16}$ Intracerebroventricular (ICV) injection of AgRP increases feeding ${ }^{19}$ that is mediated by competitive antagonism at melanocortin receptors (MCRs). ${ }^{20} \mathrm{AgRP}$ is a potent antagonist of MCRs involved in weight regulation. ${ }^{21,22}$ $\alpha$-melanocyte stimulating hormone ( $\alpha-\mathrm{MSH})$, a natural antagonist of AgRP, stimulates MCRs in the hypothalamus ${ }^{23}$ and is considered a stable agonist on modulating the food intake. ICV injection of $\alpha$-MSH significantly suppresses food intake. ${ }^{19,24,25}$ ICV administration of $\alpha$-MSH modulates ghrelin-induced orexigenic effect. ${ }^{26}$ ICV injection of AgRP abrogates the $\alpha$-MSH-induced decrease in food intake. ${ }^{19}$ To date, the influences of AgRP activity and its interactions with acyl ghrelin on food intake, gastric emptying, small intestinal motility, as well as colonic motor and secretory functions remain poorly understood.

ICV injection of ghrelin has a potent orexigenic effect and diminishes GH release, unlike peripheral injection of ghrelin, which increases the GH release. ${ }^{17} \mathrm{ICV}$ injection of acyl ghrelin is a good model to study the role of AgRP in the ghrelin-induced hyperphagic effect and gastrointestinal motility. In this study, we used $\alpha-\mathrm{MSH}$ to modulate the regulation of ICV acyl ghrelin-induced increase in food intake, gastric emptying, the geometric center of small intestinal transit, as well as colonic motor and secretory functions in conscious rats.

\section{Materials and methods Animals}

Male Sprague Dawley rats weighing 250-320 g (7-8 weeks old) were obtained from National Yang-Ming University
Laboratory Animal Center, Taipei, Taiwan. The rats were kept in rooms with controlled illumination (light period: 8 AM-8 PM), humidity $(60 \% \pm 10 \%)$, and temperature $\left(22.5^{\circ} \mathrm{C} \pm 1.5^{\circ} \mathrm{C}\right)$ with free access to water and laboratory chow pellets (BioLASCO Taiwan Co., Ltd., Taipei, Taiwan). This study was approved by the Institutional Animal Care and Use Committee (IACUC) of the Taipei Veterans General Hospital, Taiwan, and all the experiments were conducted after $8 \mathrm{AM}$ in conscious rats and were in accordance with the guidelines approved by the IACUC.

\section{Implantation of an ICV catheter}

For this purpose, the rats were anesthetized with intraperitoneal (IP) injection of sodium pentobarbital $(50 \mathrm{mg} / \mathrm{kg}$, Nembutal; Abbott Laboratories, Abbott Park, IL, USA) and were placed in a stereotaxic apparatus (Benchmark ${ }^{\mathrm{TM}}$; myNeuroLab, St Louis, MO, USA); then, they received an implant of a guide cannula (25-gauge; Eicom, Kyoto, Japan), which reached the right lateral ventricle. The coordinates in the stereotaxic apparatus were $0.8 \mathrm{~mm}$ posterior to bregma, $1.4 \mathrm{~mm}$ right lateral to the midline, and $4.5 \mathrm{~mm}$ below the outer surface of the skull using a stereotaxic frame with the incisor bar set within the horizontal plane passing through the bregma and lambda. ${ }^{27,28}$ Securing of the guide cannula, insertion of a dummy cannula (Eicom) into the guide cannula, and placement of a screw cap (Eicom) were performed as described in our previous studies. ${ }^{29,30}$ The rats were isolated and given at least 7 days for full recovery before performing the studies of food intake, gastric emptying, small intestinal transit, colonic transit time (CTT), fecal pellet output, and total fecal weight after the implantation of ICV catheters. All ICV injections lasted for $60 \mathrm{~s}$ in the total volume of $10 \mu \mathrm{L}$ via AMI-5 (Eicom).

\section{Implantation of the colonic catheter}

The rats were anesthetized by IP administration of sodium pentobarbital $(50 \mathrm{mg} / \mathrm{kg}$, Nembutal; Abbott Laboratories). After laparotomy of the lower abdomen, the proximal colon was exposed and a catheter ( $3 \mathrm{Fr}, 1 \mathrm{~mm}$ diameter; ATOM, Tokyo, Japan) was implanted into the proximal colon, $2 \mathrm{~cm}$ distal from the cecocolonic junction. ${ }^{31-34}$ The catheter was fixed with a purse-string suture at the colonic wall and routed subcutaneously to the interscapular region, exteriorized through the skin, and secured together with an intravenous catheter for intracolonic administration of the dye marker. ${ }^{31-34}$ The animals were allowed to recover for 7 days before simultaneous measurement of colonic motor and secretory functions was performed. 


\section{Preparation of drugs}

Rat $O$-n-octanoylated ghrelin (American Peptide Co., Sunnyvale, CA, USA) and $\alpha$-MSH (Tocris Bioscience, Bristol, UK) were kept in powder form at $-20^{\circ} \mathrm{C}$, and dissolved in sterile, pyrogen-free $0.9 \%$ saline (Otsuka, Tokyo, Japan) immediately before use.

\section{Food intake analysis}

The measurement of food intake was performed as in our previous studies with a slight modification. ${ }^{27,28}$ In short, the cumulative food intake was recorded and calculated at 1, 2, $4,8,12$, and $24 \mathrm{~h}$ immediately after ICV injection. The total volume of ICV injection was $10 \mu \mathrm{L}$ for each rat. Food intake was determined by measuring the difference between the preweighed standard chow and the weight of chow at each time point. At least 7 days before the food intake tests, all rats were allowed to fully acclimate to the environments. Lightphase experiments on freely fed rats were started at $8 \mathrm{AM}$. Before the tests, the rats were given free access to food and water (were freely fed). A standard diet (BioLASCO Taiwan Co., Ltd.) was provided.

\section{Gastric emptying and small intestinal transit of a charcoal, non-nutrient, semi-liquid meal}

After deprivation of food for $16 \mathrm{~h}$ with free access to water, non-nutrient semi-liquid gastric emptying was measured in conscious rats (food-deprived rats). The total volume of ICV injection was $10 \mu \mathrm{L}$ for each rat. Fifteen minutes after ICV injection, conscious rats were gavaged via a catheter (PE-205, inner diameter: $1.67 \mathrm{~mm}$, outer diameter: $2.42 \mathrm{~mm}$; ClayAdam, Parsippany, NJ, USA) with a test meal containing $\mathrm{Na}_{2}{ }^{51} \mathrm{CrO}_{4}(0.5 \mu \mathrm{Ci} / \mathrm{mL})$ and $10 \%$ charcoal in physiologic saline $(3 \mathrm{~mL} / \mathrm{kg}$ ) on the day of the experiment (at $\sim 9 \mathrm{AM})$. The test meal was continuously stirred before intubation. Additional air $(0.5 \mathrm{~mL})$ was added to flush the residual charcoal suspension remaining in the catheter. Thirty minutes later, the rats were decapitated. ${ }^{30}$ The details are described elsewhere..$^{35}$ The radioactivity of the stomach and each segment of the small intestine was measured in an automatic $\gamma$ counter (1470 Wizard; Pharmacia, Turku, Finland). Semi-liquid gastric emptying was calculated as: (total radioactivity in the small intestine/total radioactivity in the stomach and small intestine) $\times 100 \%$, at $30 \mathrm{~min}$ after gavage. ${ }^{35}$ Small intestinal transit was assessed by analyzing the geometric centric center of radioactivity distribution with the 10 equal segments. The geometric center was calculated by summation of radioactivity percentages measured in each segment multiplied by the segment number. ${ }^{35}$ The running percentage of the small intestine was calculated as the front, which indicated the leading edge of charcoal moving within the intestine. ${ }^{35}$

\section{Colonic motor and secretory function tests}

Simultaneous measurement of the CTT, fecal pellet output, and total fecal weight

The methods used for measurements of colonic motor and secretory functions were modified from our previous studies. ${ }^{31-34}$ The rats were accustomed to single housing for 7 days before the experiment. We used an enteral nonabsorbable dye marker, trypan blue, to calculate the CTT (Sigma Chemical Co., St Louis, MO, USA). Trypan blue $(0.2 \mathrm{~mL})$ was injected into the proximal colon through the positioned catheter, and followed by a $0.2 \mathrm{~mL}$ saline flush for $10 \mathrm{~min}$ after the ICV injection of acyl ghrelin $(1.0 \mathrm{nmol} /$ rat). The CTT was defined as the time interval between the dye injection and the discharge of the first blue pellet.

The total number of pellets was recorded for $1 \mathrm{~h}$ following the intracolonic injection of trypan blue. The total fecal material was collected for $1 \mathrm{~h}$ following the intracolonic injection of trypan blue, weighed, and then desiccated overnight at $50^{\circ} \mathrm{C}$. The fecal fluid and solid output were calculated from the total and dry weights. ${ }^{31,32,34}$

\section{Experimental protocols}

\section{Analysis of the effects of ICV injection of} $O-n$-octanoylated ghrelin and $\alpha-\mathrm{MSH}$ on food intake

In the first experiment, food intake of conscious rats was measured in a freely fed state. The vehicle ( $5 \mu \mathrm{L}$ of saline) or $\alpha$-MSH (1.0 or $2.0 \mathrm{nmol} / \mathrm{rat})$ was injected ICV just before the administration of another vehicle ( $5 \mu \mathrm{L}$ saline) or $O$-n-octanoylated ghrelin $(0.1 \mathrm{nmol} / \mathrm{rat})$, performed as in our previous studies. ${ }^{27,36}$ The cumulative food intake was recorded at 1, 2, 4, 8, 12, and $24 \mathrm{~h}$ after the injection. The optimal dose of $O$ - $n$-octanoylated ghrelin $(0.1 \mathrm{nmol} / \mathrm{rat})$ was chosen according to the dose-response relation determined in our previous food intake experiments in conscious freely fed rats. ${ }^{27,28}$ The ratio of $\alpha-\mathrm{MSH} / O-n$-octanoylated ghrelin was derived from data described in our previous study. ${ }^{27,29}$

\section{Analysis of the effects of ICV injection of $O-n$ - octanoylated ghrelin and $\alpha-\mathrm{MSH}$ on gastric emptying} In the second experiment, the vehicle ( $5 \mu \mathrm{L}$ saline) or $\alpha-\mathrm{MSH}$ (1.0 or $2.0 \mathrm{nmol} / \mathrm{rat}$ ) was injected ICV immediately before the administration of another vehicle ( $5 \mu \mathrm{L}$ saline) or $O-n$ octanoylated ghrelin $(0.1 \mathrm{nmol} / \mathrm{rat})$. The optimal dose of 
$O$ - $n$-octanoylated ghrelin $(0.1 \mathrm{nmol} / \mathrm{rat})$ in terms of the effect on gastric emptying was chosen according to our previous study. ${ }^{30}$ The ratio of $\alpha$-MSH/ $O$ - $n$-octanoylated ghrelin was derived from data described in our previous study. ${ }^{29,36}$

Analysis of the effects of ICV injection of O-noctanoylated ghrelin and $\alpha-\mathrm{MSH}$ on the geometric center and running percentage of small intestinal transit

In the third experiment, the vehicle ( $5 \mu \mathrm{L}$ saline) or $\alpha-\mathrm{MSH}$ ( 1.0 or $2.0 \mathrm{nmol} / \mathrm{rat}$ ) was injected ICV just before the administration of another vehicle ( $5 \mu \mathrm{L}$ saline) or $O-n$-octanoylated ghrelin $(0.1 \mathrm{nmol} / \mathrm{rat})$. The optimal dose of $O$ - $n$-octanoylated ghrelin $(0.1 \mathrm{nmol} / \mathrm{rat})$ in terms of the effect on the geometric center and running percentage was modified according to our previous study. ${ }^{35}$ The ratio of $\alpha$-MSH/O-n-octanoylated ghrelin was derived from our previous data. ${ }^{29,36}$

Analysis of the effects of ICV injection of O-noctanoylated ghrelin and $\alpha-\mathrm{MSH}$ on the colonic motor and secretory functions

In the fourth experiment, the rats received an ICV injection of the vehicle ( $5 \mu \mathrm{L}$ saline) or $\alpha-\mathrm{MSH}$ ( 1.0 or $2.0 \mathrm{nmol} / \mathrm{rat})$ just before the administration of another vehicle ( $5 \mu \mathrm{L}$ saline) or $O$ - $n$-octanoylated ghrelin $(0.1 \mathrm{nmol} / \mathrm{rat})$. The dose of $O-n$ octanoylated ghrelin $(0.1 \mathrm{nmol} / \mathrm{rat})$ was chosen from the experiments of gastric emptying and small intestinal transit. The ratio of $\alpha$-MSH/ $O$ - $n$-octanoylated ghrelin was derived from our previous data. ${ }^{29,36}$

\section{Statistical analyses}

All results were expressed as mean \pm standard error of the mean. One-way analysis of variance followed by the StudentNewman-Keuls post hoc test was used to analyze differences among groups, when we analyzed one-variable experiments with more than two groups. Differences were considered statistically significant at $P<0.05$.

\section{Results}

\section{Effects of ICV injection of $O-n-$} octanoylated ghrelin and $\alpha-M S H$ on spontaneous food intake in freely fed rats In our study, ICV injection of $\alpha$-MSH ( 1.0 and $2.0 \mathrm{nmol} /$ rat) showed a tendency to decrease the cumulative food intake at $1,2,4$, and $8 \mathrm{~h}(P>0.05$, Figure $1 \mathrm{~A}-\mathrm{D})$ and of $1.0 \mathrm{nmol} / \mathrm{rat}$ $\alpha$-MSH significantly decreased food intake at $12 \mathrm{~h}$, compared to the vehicle group $(P<0.05$, Figure $1 \mathrm{E})$.

On the other hand, ICV injection of $O$ - $n$-octanoylated ghrelin $(0.1 \mathrm{nmol} / \mathrm{rat})$ significantly increased the cumulative food intake at $1,2,4$, and $8 \mathrm{~h}$ as compared with the vehicle group $(P<0.001$, Figure $1 \mathrm{~A}-\mathrm{D})$. ICV injection of $O-n$ octanoylated ghrelin $(0.1 \mathrm{nmol} / \mathrm{rat})$ did not increase the food intake at 12 and $24 \mathrm{~h}(P>0.05$, Figure $1 \mathrm{E}$ and F). ICV injection of $\alpha$-MSH (1.0 nmol/rat) significantly attenuated the ghrelin-induced increase of food intake at 1, 2, 4, and $8 \mathrm{~h}(P<0.05$, Figure 1A-D). Moreover, ICV injection of $\alpha$-MSH $(2.0 \mathrm{nmol} / \mathrm{rat})$ significantly decreased the intake at $1 \mathrm{~h}(P<0.001$, Figure $1 \mathrm{~A}), 2 \mathrm{~h}(P<0.05$, Figure $1 \mathrm{~B}), 4 \mathrm{~h}$ $(P<0.05$, Figure 1C), $8 \mathrm{~h}(P<0.01$, Figure $1 \mathrm{D})$, and at $12 \mathrm{~h}$ $(P<0.01$, Figure 1E).

\section{Effects of ICV injection of $O-n-$ octanoylated ghrelin and $\alpha-\mathrm{MSH}$ on gastric emptying}

ICV injection of $O$ - $n$-octanoylated ghrelin $(0.1 \mathrm{nmol} / \mathrm{rat})$ significantly enhanced non-nutrient semi-liquid gastric emptying, as compared with the vehicle group $(P<0.001$, Figure 2). In contrast, ICV injection of $\alpha-\mathrm{MSH}$ (1.0 and $2.0 \mathrm{nmol} / \mathrm{rat}$ ) did not affect gastric emptying. Furthermore, pretreatment with ICV injection of $\alpha$-MSH (1.0 and $2.0 \mathrm{nmol} / \mathrm{rat}$ ) failed to modify the acyl ghrelin-induced gastroprokinetic effect $(P>0.05$, Figure 2$)$.

\section{Effects of ICV injection of $O-n$ - octanoylated ghrelin and/or $\alpha-M S H$ on the geometric center and running percentage of small intestinal transit}

ICV injection of $O-n$-octanoylated ghrelin $(0.1 \mathrm{nmol} / \mathrm{rat})$ significantly increased the geometric center and running percentage of small intestinal transit, as compared with the vehicle $(P<0.001$, Figure $3 \mathrm{~A}$ and B). By contrast, ICV injection of $\alpha$-MSH (1.0 and $2.0 \mathrm{nmol} / \mathrm{rat})$ did not affect small intestinal transit in terms of either geometric center or running percentage. ICV injection of $\alpha$-MSH at a higher dose, $2.0 \mathrm{nmol} / \mathrm{rat}$, significantly attenuated the central acyl ghrelin-induced increase in the geometric center of small intestinal transit $(P<0.001$, Figure 3A). On the other hand, ICV injection of $\alpha$-MSH $(1.0$ and $2.0 \mathrm{nmol} / \mathrm{rat})$ failed to alter the central acyl ghrelin-induced increase in the running percentage of small intestinal transit ( $P>0.05$, Figure $3 \mathrm{~B})$.

\section{Effects of ICV injection of $O-n$ -} octanoylated ghrelin and/or $\alpha-\mathrm{MSH}$ on the CTT, fecal pellet output, total fecal weight, fecal fluid and dried solid weight

ICV injection of $O-n$-octanoylated ghrelin $(0.1 \mathrm{nmol} / \mathrm{rat})$ significantly decreased the CTT $(P<0.05$, Figure 4$)$ and 

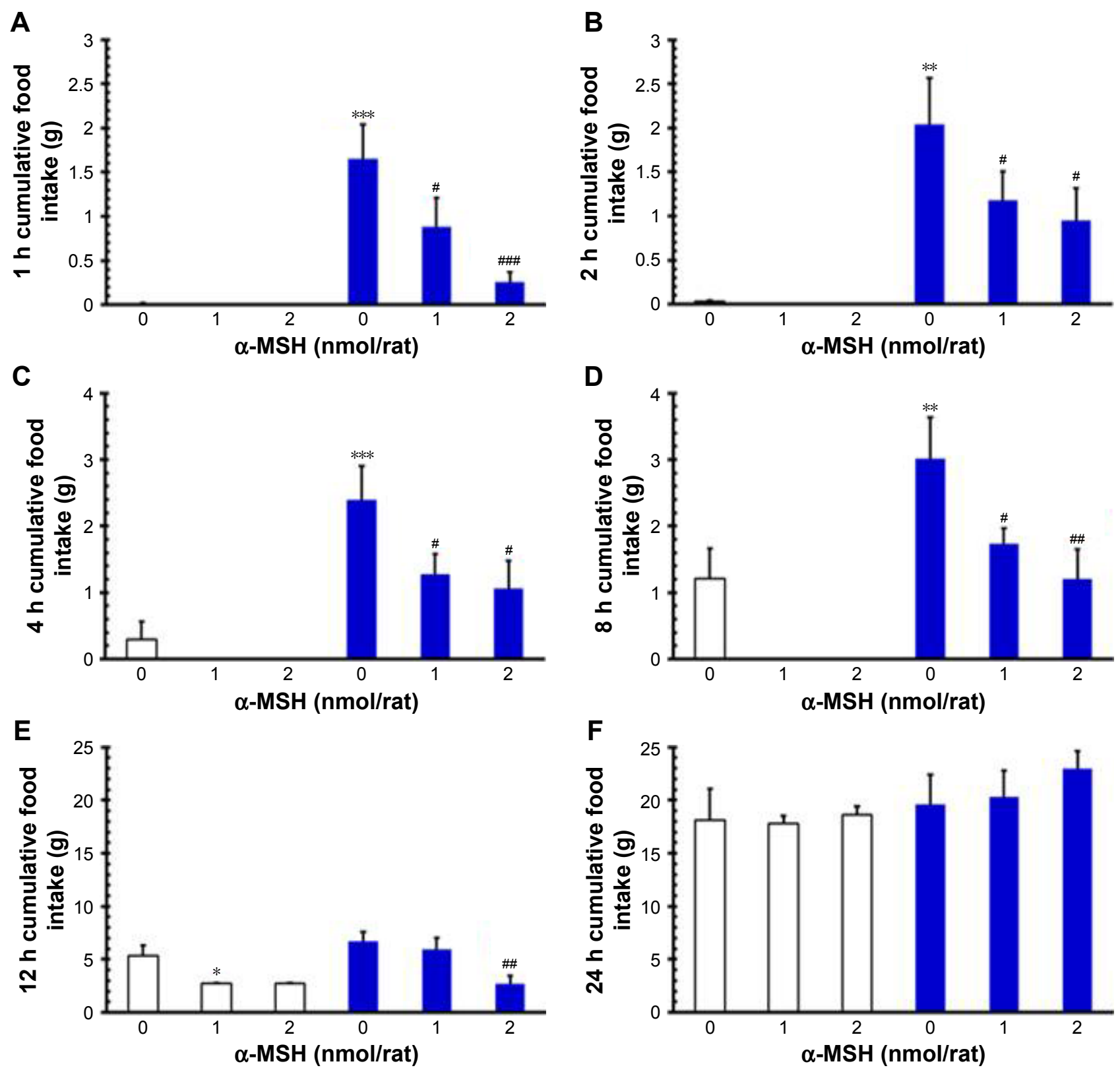

$\square$ Vehicle $\quad$ O-n-octanoylated ghrelin $(0.1 \mathrm{nmol} / \mathrm{rat})$

Figure I The effects of ICV injection of $O-n$-octanoylated ghrelin and $\alpha-M S H$ (I.0 or $2.0 \mathrm{nmol} / \mathrm{rat})$ on cumulative food intake in freely fed rats. After ICV injection of saline (vehicle) or $\alpha-\mathrm{MSH}, \mathrm{O}-\mathrm{n}$-octanoylated ghrelin was injected ICV immediately, and cumulative food intake was measured at I, 2, 4, 8, I2, and 24 h.

Notes: The results are shown in $(\mathbf{A}-\mathbf{F})$, respectively. Data are presented as mean $\pm S E M ; * P<0.05$, $* * P<0.01$, $* * * P<0.00$ I, compared to the vehicle-injected group; ${ }^{*} P<0.05$, $P<0.0$ I, $P<0.00$ I, compared to the $O$ - $n$-octanoylated ghrelin-injected control group. $n=12$ rats in each group.

Abbreviations: $\alpha-\mathrm{MSH}, \alpha$-melanocyte stimulating hormone; ICV, intracerebroventricular; SEM, standard error of the mean.

increased the fecal pellet output $(P<0.01$, Figure 5), total fecal weight $(P<0.01$, Figure 6$)$, and fecal dried solid weight $(P<0.01$, Figure 7$)$. In contrast, ICV injection of $\alpha$-MSH ( 1.0 and $2.0 \mathrm{nmol} / \mathrm{rat}$ ) did not affect the CTT, fecal pellet output, total fecal weight, fecal fluid weight, or fecal dried solid weight. Furthermore, ICV injection of $\alpha$-MSH ( 1.0 and $2.0 \mathrm{nmol} / \mathrm{rat}$ ) had no effect on the ghrelin-induced decrease in CTT (Figure 4) or fecal fluid weight (Figure 8). However, ICV injection of $\alpha-\mathrm{MSH}(1.0$ and $2.0 \mathrm{nmol} / \mathrm{rat})$ significantly attenuated the ghrelin-induced increase in fecal pellet output and total fecal weight $(P<0.05$, Figure 5 and $P<0.01$, Figure 6). ICV injection of $\alpha-\mathrm{MSH}(1.0 \mathrm{nmol} / \mathrm{rat})$ also significantly decreased the ghrelin-induced increase in fecal dried solid weight $(P<0.05$, Figure 7).

\section{Discussion}

In our study, ICV injection of $O-n$-octanoylated ghrelin $(0.1 \mathrm{nmol} / \mathrm{rat})$ significantly increased the cumulative food 


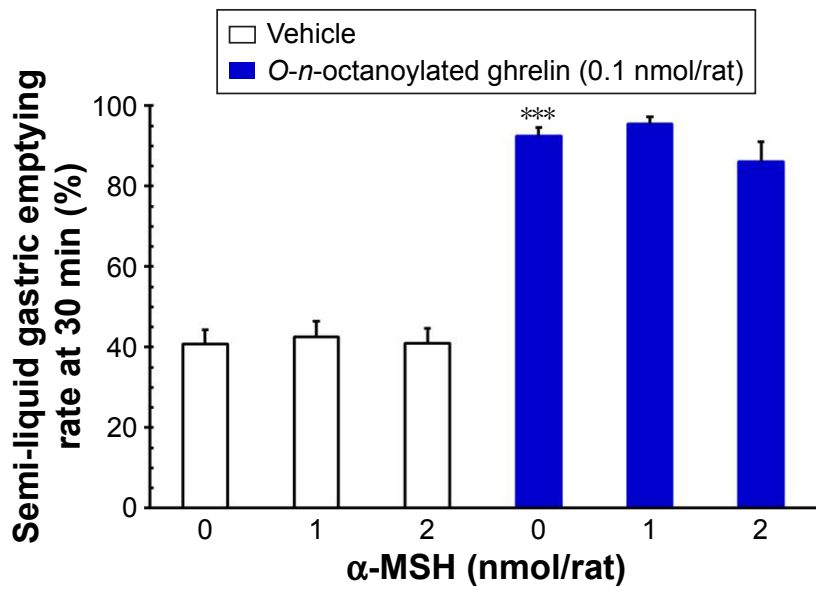

Figure 2 The effects of ICV injection of $O-n$-octanoylated ghrelin and $\alpha-M S H$ (I.0 or $2.0 \mathrm{nmol} / \mathrm{rat}$ ) on $30 \mathrm{~min}$ charcoal, non-nutrient, semi-liquid gastric emptying rate in conscious rats deprived of food for $16 \mathrm{~h}$.

Notes: After ICV injection of saline (vehicle) or $\alpha-M S H ~(1.0$ or $2.0 \mathrm{nmol} / \mathrm{rat}$ ), $O$-n-octanoylated ghrelin was ICV injected immediately. O-n-octanoylated ghrelin (0.I nmol/rat) significantly enhanced gastric emptying. $\alpha-\mathrm{MSH}$ (I.0 or $2.0 \mathrm{nmol} / \mathrm{rat}$ ) had no effect of attenuating on the enhancement of gastric emptying induced by $O-n-$ octanoylated ghrelin. Data are presented as mean \pm SEM. $* * * P<0.001$, compared to the vehicle-injected group. $n=8$ rats in each group.

Abbreviations: $\alpha-\mathrm{MSH}, \alpha$-melanocyte stimulating hormone; ICV, intracerebroventricular; SEM, standard error of the mean.

intake at 1, 2, 4, and $8 \mathrm{~h}$, whereas ICV injection of $\alpha$-MSH (1.0 and $2.0 \mathrm{nmol} / \mathrm{rat}$ ), a natural antagonist of AgRP, significantly attenuated the central acyl ghrelin-elicited food intake. In addition, $O$ - $n$-octanoylated ghrelin significantly accelerated the rate of semi-liquid gastric emptying at $30 \mathrm{~min}$ and increased the geometric center and the running percentage of small intestinal transit. Our study first showed that $\alpha$-MSH (2.0 $\mathrm{nmol} / \mathrm{rat})$ significantly attenuated the increase in the geometric center, but not in the running percentage of the small intestinal transit induced by central acyl ghrelin. $\alpha$-MSH also attenuated the central acyl ghrelin-induced increase in fecal pellet output, total fecal weight, and fecal dried solid weight, but not the CTT or fecal fluid weight. In summary, the orexigenic properties of AgRP and the anorectic effect of $\alpha-\mathrm{MSH}$ are both mediated by MCRs. Central administration of an MCR antagonist has been reported to prevent cachexia-related symptoms ${ }^{37}$ and reverse cancer anorexia. ${ }^{38}$

In the food intake experiment, plasma acyl ghrelin concentration was demonstrated to be low in freely fed rats because plasma acyl ghrelin reached a peak during fasting 39,40 and decreased to the nadir level postprandially. ${ }^{41}$ Both IP and ICV administration of ghrelin stimulate increased food intake quickly, ${ }^{42}$ but the effect of ICV administration persisted for 8 h. ${ }^{27,42}$ Our results revealed that ICV injection of acyl ghrelin significantly increased food intake at 1, 2, 4 , and $8 \mathrm{~h}$ in freely fed rats and did not increase intake at 12 or $24 \mathrm{~h}$; these results agree with our previous results ${ }^{27}$ and the results of others. ${ }^{18,42}$ This finding confirmed acyl ghrelin-induced hyperphagia. ${ }^{27,28,42}$ Centrally administered acyl ghrelin significantly induced increase in food intake for up to $8 \mathrm{~h}^{27,42}$ and was suppressed by $\alpha$-MSH $(2.0 \mathrm{nmol} /$ rat) administration at $2 \mathrm{~h}^{26}$ Our results show an extended suppression effect of 1.0 and $2.0 \mathrm{nmol} / \mathrm{rat} \alpha-\mathrm{MSH}$ for up to $8 \mathrm{~h}$. These results are compatible with ICV administration of $\alpha$-MSH alone having a dose-dependent (1-6 nmol/rat) reducing effect on food intake for up to $8 \mathrm{~h}$ and no effect
A

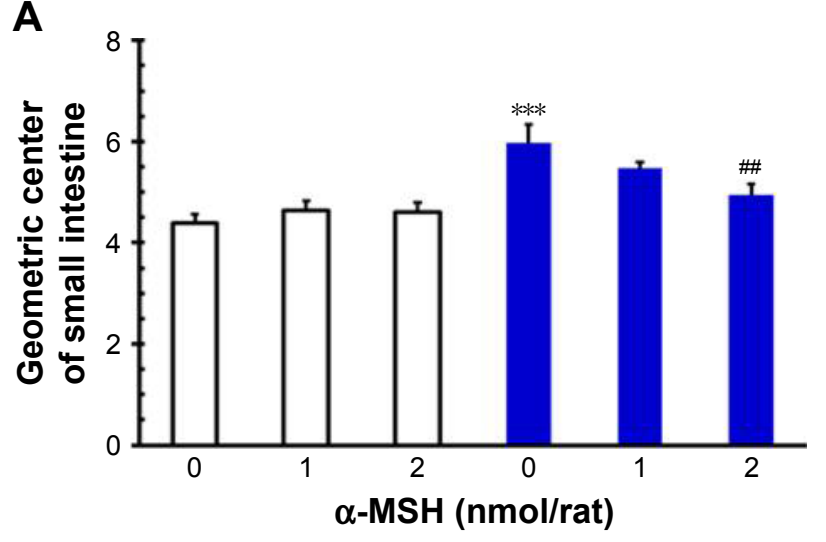

B

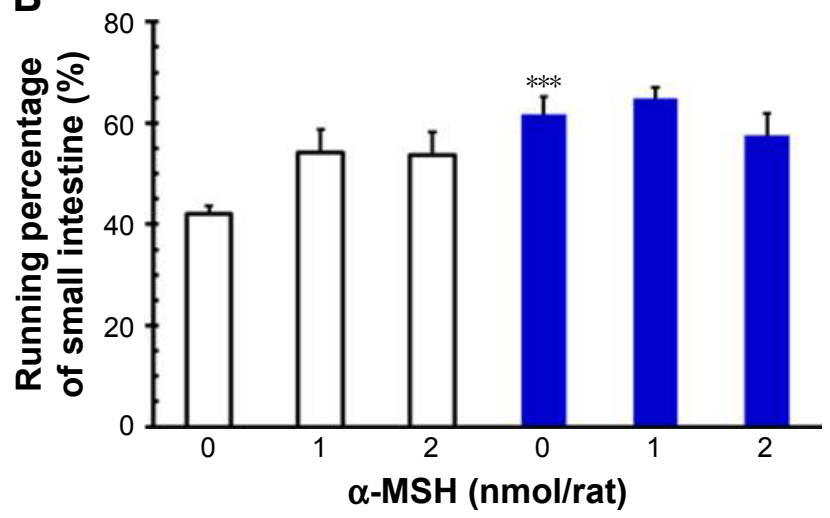

$\square$ Vehicle $\square$ O-n-octanoylated ghrelin $(0.1 \mathrm{nmol} / \mathrm{rat})$

Figure 3 The effects of ICV injection of $O-n$-octanoylated ghrelin and $\alpha-M S H(I .0$ or $2.0 \mathrm{nmol} / \mathrm{rat})$ on the geometric center and the running percentage of small intestinal transit in $16 \mathrm{~h}$ food-deprived conscious rats.

Notes: ICV injection of $O-n$-octanoylated ghrelin significantly increased the geometric center of small intestinal transit, and 2 nmol/rat $\alpha-M S H$ significantly attenuated this

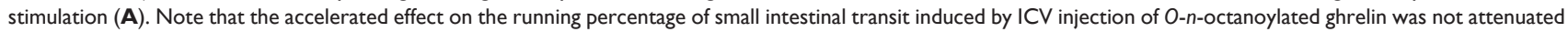

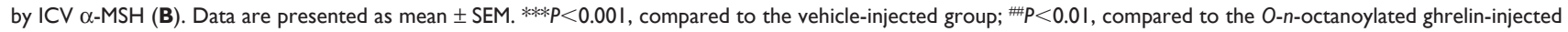
control group. $n=8$ rats in each group.

Abbreviations: $\alpha-\mathrm{MSH}, \alpha$-melanocyte stimulating hormone; ICV, intracerebroventricular; SEM, standard error of the mean. 


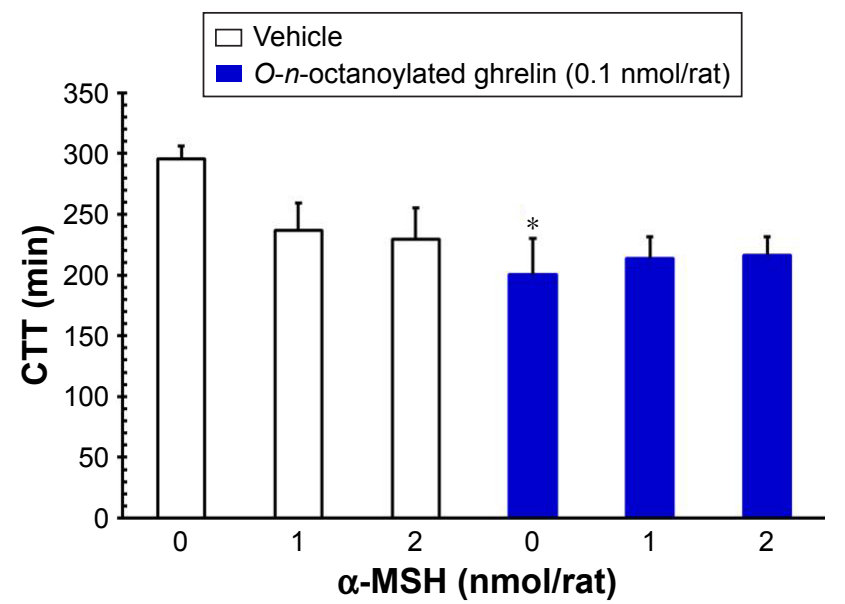

Figure 4 The effects of ICV injection of $O-n$-octanoylated ghrelin and $\alpha-M S H$ ( 1.0 or $2.0 \mathrm{nmol} / \mathrm{rat}$ ) on CTT.

Notes: ICV injection of $O-n$-octanoylated ghrelin significantly decreased CTT. $\alpha-\mathrm{MSH}$ ( 1.0 or $2.0 \mathrm{nmol} / \mathrm{rat}$ ) had no effect on the decrease of CTT induced by $0-n$ octanoylated ghrelin. Data are presented as mean \pm SEM. $* P<0.05$, compared to the vehicle-injected group. $n=8$ rats in each group.

Abbreviations: $\alpha-\mathrm{MSH}, \alpha$-melanocyte stimulating hormone; CTT, colonic transit time; ICV, intracerebroventricular; SEM, standard error of the mean.

at 24 h. ${ }^{43}$ Our results suggested that $\alpha-\mathrm{MSH}$, by influencing AgRP activity, partly abrogated the effect of acyl ghrelin on food intake.

In the gastric emptying experiment, plasma acyl ghrelin was elevated in food-deprived rats, ${ }^{39}$ while the NPY/AgRP neurons were in the activated state. Acyl ghrelin has been reported to accelerate gastric emptying in conscious fooddeprived rats ${ }^{30,36}$ and humans. ${ }^{44,45}$ Our results are in agreement

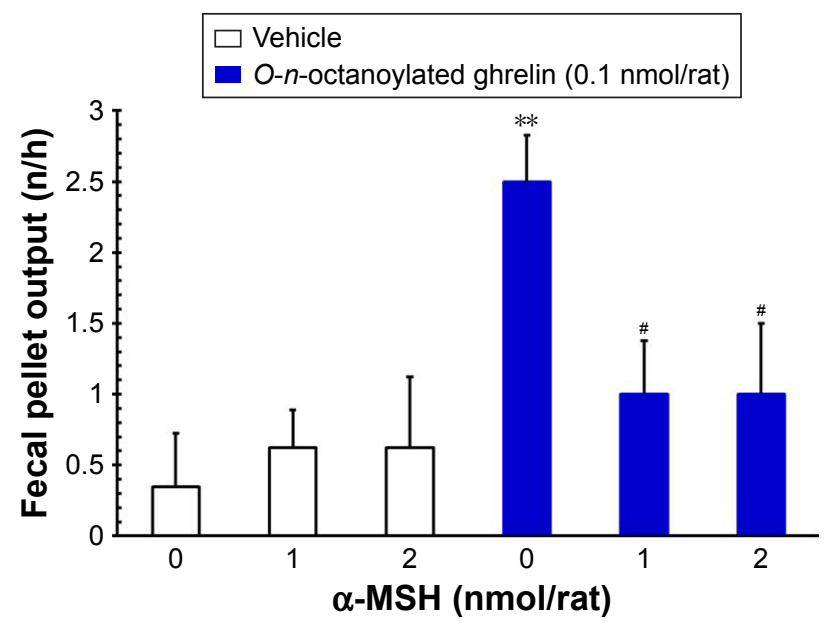

Figure 5 The effects of ICV injection of $O-n$-octanoylated ghrelin and $\alpha-M S H$ (I.0 or $2.0 \mathrm{nmol} / \mathrm{rat}$ ) on fecal pellet output.

Notes: ICV injection of $O$-n-octanoylated ghrelin significantly increased fecal pellet output. $\alpha-\mathrm{MSH}$ (I.0 or $2.0 \mathrm{nmol} / \mathrm{rat}$ ) attenuated the increase in fecal pellet output induced by acyl ghrelin. Data are presented as mean \pm SEM. $* * P<0.01$, compared to the vehicle-injected group; ${ }^{P}<0.05$, compared to the $O$-n-octanoylated ghrelininjected control group. $n=8$ rats in each group.

Abbreviations: $\alpha-\mathrm{MSH}, \alpha$-melanocyte stimulating hormone; ICV, intracerebroventricular; SEM, standard error of the mean.

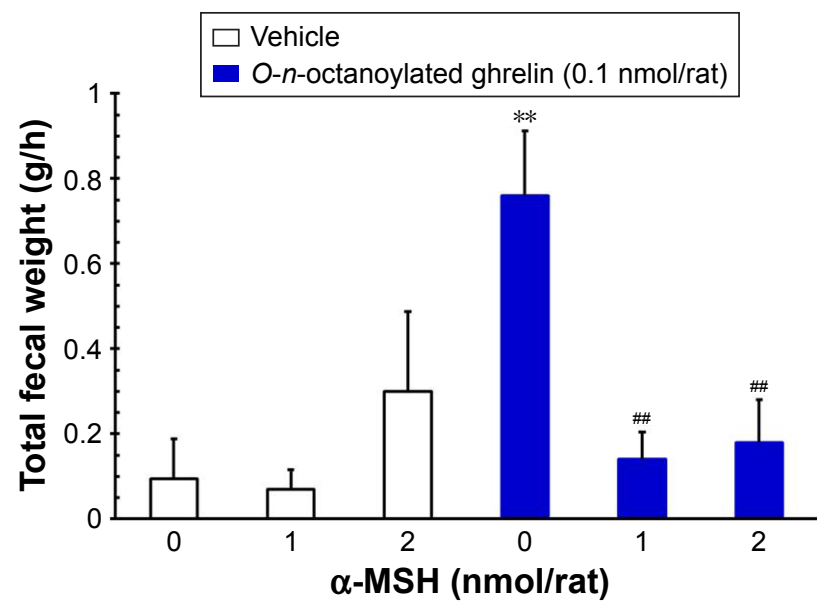

Figure 6 The effects of ICV injection of O-n-octanoylated ghrelin and $\alpha-M S H$ ( I.0 or $2.0 \mathrm{nmol} / \mathrm{rat}$ ) on total fecal weight.

Notes: ICV injection of $O-n$-octanoylated ghrelin significantly increased total fecal weight. $\alpha-\mathrm{MSH}(1.0$ or $2.0 \mathrm{nmol} / \mathrm{rat})$ attenuated the increase in total fecal weight induced by acyl ghrelin. Data are presented as mean \pm SEM. $* * P<0.0$ I, compared to the vehicle-injected group; ${ }^{\#} P<0.0$ I, compared to the $O$ - $n$-octanoylated ghrelininjected control group. $n=8$ rats in each group.

Abbreviations: $\alpha-\mathrm{MSH}$, $\alpha$-melanocyte stimulating hormone; ICV, intracerebroventricular; SEM, standard error of the mean.

with these data. The ghrelin-increased gastric emptying may be mediated by the vagal nerve or the enteric neural pathway and their afferent activity. ${ }^{46,47}$ Peripheral injection of acyl ghrelin induces fasted-state motor activity in both stomach and duodenum, whereas the acyl ghrelin-induced stimulation of stomach and duodenum is blocked by immunoneutralization of NPY in the brain of rats. ${ }^{48}$ On the other hand, NPY alone has been demonstrated to suppress gastric

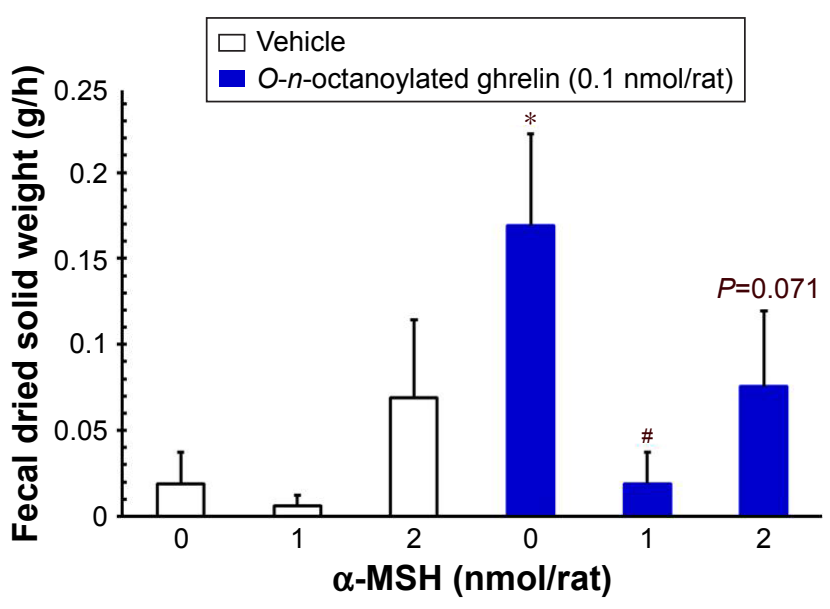

Figure 7 The effects of ICV injection of O-n-octanoylated ghrelin and $\alpha-M S H$ ( I.0 or $2.0 \mathrm{nmol} / \mathrm{rat}$ ) on fecal dried solid weight.

Notes: ICV injection of $O$-n-octanoylated ghrelin significantly increased fecal dried solid weight. $\alpha-\mathrm{MSH}$ (I.0 nmol/rat) attenuated the increase in fecal dried solid weight induced by acyl ghrelin. Data are presented as mean \pm SEM. $* P<0.05$, compared to the vehicle-injected group; ${ }^{\sharp P}<0.05$, compared to the $O$ - $n$-octanoylated ghrelininjected control group. $n=8$ rats in each group.

Abbreviations: $\alpha-M S H, \alpha$-melanocyte stimulating hormone; ICV, intracerebroventricular; SEM, standard error of the mean. 


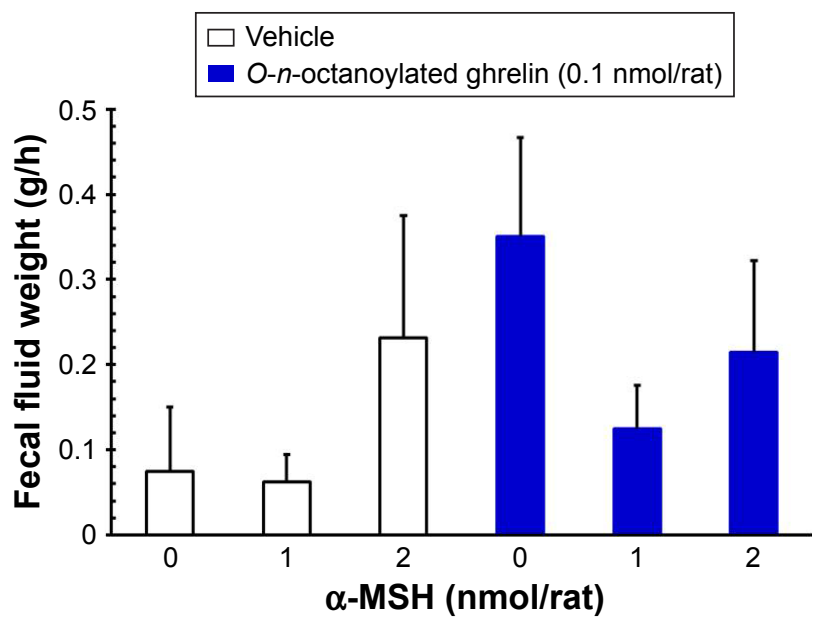

Figure 8 The effects of ICV injection of $O-n$-octanoylated ghrelin and $\alpha-M S H$ ( I.0 or $2.0 \mathrm{nmol} / \mathrm{rat}$ ) on fecal fluid weight.

Notes: ICV injection of $O-n$-octanoylated ghrelin has a trend in increasing the fecal fluid weight. Data are presented as mean \pm SEM. $n=8$ rats in each group.

Abbreviations: $\alpha$-MSH, $\alpha$-melanocyte stimulating hormone; ICV, intracerebroventricular; SEM, standard error of the mean.

emptying ${ }^{49,50}$ and small intestinal transit ${ }^{49}$ in rats, but has no significant effect on gastric emptying in humans. ${ }^{51}$ Contrary to the comprehensive exploration of NPY, little is known about the influence of AgRP on gut motility. Our study is the first report to show the influence of $\alpha-\mathrm{MSH}$ on gastric emptying and small intestinal transit in rats. In our study, $\alpha$-MSH did not alter the gastric emptying accelerated by central acyl ghrelin stimulation. These results indicate that central acyl ghrelin-induced acceleration of gastric emptying is not mediated by MCRs in the brain.

The geometric center and the running percentage of small intestine were calculated in food-deprived rats, and the plasma levels of acyl ghrelin were expected to be elevated..$^{39,40}$ Administration of acyl ghrelin has been reported to accelerate intestinal transit ${ }^{46,52}$ and to have the ability to normalize the burn-induced delay in intestinal transit. ${ }^{53}$ $\alpha$-MSH induced the release of peptide YY, ${ }^{54}$ while peptide YY had the ability to inhibit the intestinal transit. ${ }^{55,56}$ In our study, ICV injection of acyl ghrelin significantly increased both the geometric center and the running percentage of small intestinal transit. Furthermore, higher dose of $\alpha$-MSH ( $2 \mathrm{nmol} / \mathrm{rat}$ ) significantly attenuated the central acyl ghrelininduced increase in the geometric center, but not the running percentage, of small intestinal transit. These results support the hypothesis that central acyl ghrelin-induced increase of small intestinal transit is at least partly mediated by MCRs in the brain.

The colonic motor function is usually evaluated by measuring CTT and fecal pellet output. The use of trypan blue is a good method for measuring the entire colonic motor function, ${ }^{57,58}$ as shown in our previous studies. ${ }^{33,34}$ Measuring the fecal pellet output is an easy and simple method of assessing colonic motor function. ${ }^{59,60}$ ICV injection of acyl ghrelin has been proposed to decrease the CTT ${ }^{33,58}$ and increase the fecal pellet output. ${ }^{33}$ Central administration of ghrelin has been shown to modulate the peripheral gastrointestinal motor functions at the paraventricular nucleus via the NPY1 receptor mechanism. ${ }^{57,58}$ The orexigenic effect of acyl ghrelin has been shown through NPY/AgRP neurons in the hypothalamus. ${ }^{10-12}$ However, the effect of central acyl ghrelin through AgRP on colonic motor functions via MCRs is still uninvestigated. Our study showed that $\alpha-\mathrm{MSH}$ did not restore central acyl ghrelin-induced accelerated CTT, but attenuated the increase in fecal pellet output and total fecal weight. These results suggested that central acyl ghrelin-induced enhancement of distal colonic motility and colonic secretion is, at least partly, mediated by MCRs in the brain. As MCRs have been reported to be hyperactive in cancer cachexia, ${ }^{61}$ and plasma levels of acyl ghrelin have been shown to be compensatory but insufficiently increased in tumor-bearing rats compared to paired-fed controls, ${ }^{62}$ the interplays between acyl ghrelin and MCRs from our studies may provide a new therapeutic avenue for ameliorating anorexia and constipation during human negative energy balance conditions.

\section{Conclusion}

This study is the first to show the influence of $\alpha-\mathrm{MSH}$ (and its interplay with acyl ghrelin) on non-nutrient semi-liquid gastric emptying and small intestinal transit in rats. ICV injection of acyl ghrelin elicited food intake, accelerated gastric emptying, increased the geometric center and running percentage of small intestinal transit, decreased CTT, and increased fecal pellet output, total fecal weight, and fecal dried solid weight. $\alpha-\mathrm{MSH}$ attenuated central acyl ghrelininduced stimulation of hyperphagia, increase in geometric center of small intestinal transit, and increase in fecal pellet output and total fecal weight, but failed to modify central acyl ghrelin-induced acceleration of gastric emptying, increase in the running percentage of small intestinal transit, and decrease in CTT.

\section{Acknowledgments}

This project was funded by grants from the Taiwan Ministry of Science and Technology (NSC 96-2320-B-010-037to Chih-Yen Chen). We would like to thank the Clinical Research Core Laboratory of Taipei Veterans General Hospital for providing experimental space and facilities. 


\section{Author contributions}

$\mathrm{HHH}, \mathrm{LYC}, \mathrm{MLD}, \mathrm{SCC}$, and CYC participated in the conception, design, and acquisition of data of the research. HHH and CYC wrote and revised the paper. All authors contributed toward data analysis, drafting and critically revising the paper, gave final approval of the version to be published, and agree to be accountable for all aspects of the work.

\section{Disclosure}

The authors report no conflicts of interest in this work.

\section{References}

1. Kojima M, Hosoda H, Date Y, Nakazato M, Matsuo H, Kangawa K. Ghrelin is a growth-hormone-releasing acylated peptide from stomach. Nature. 1999;402(6762):656-660.

2. Chen CY, Asakawa A, Fujimiya M, Lee SD, Inui A. Ghrelin gene products and the regulation of food intake and gut motility. Pharmacol Rev. 2009;61(4):430-481.

3. Baldanzi G, Filigheddu N, Cutrupi S, et al. Ghrelin and des-acyl ghrelin inhibit cell death in cardiomyocytes and endothelial cells through ERK1/2 and PI 3-kinase/AKT. J Cell Biol. 2002;159(6):1029-1037.

4. García MC, Lopez M, Alvarez CV, Casanueva F, Tena-Sempere M, Diéguez C. Role of ghrelin in reproduction. Reproduction. 2007; 133(3):531-540

5. Thompson NM, Gill DA, Davies R, et al. Ghrelin and des-octanoyl ghrelin promote adipogenesis directly in vivo by a mechanism independent of the type 1a growth hormone secretagogue receptor. Endocrinology. 2004;145(1):234-242.

6. Granata R, Settanni F, Biancone L, et al. Acylated and unacylated ghrelin promote proliferation and inhibit apoptosis of pancreatic beta-cells and human islets: involvement of $3^{\prime}, 5^{\prime}$-cyclic adenosine monophosphate/protein kinase A, extracellular signalregulated kinase 1/2, and phosphatidyl inositol 3-Kinase/Akt signaling. Endocrinology. 2007;148(2):512-529.

7. Banks WA, Tschöp M, Robinson SM, Heiman ML. Extent and direction of ghrelin transport across the blood-brain barrier is determined by its unique primary structure. J Pharmacol Exp Ther. 2002; 302(2):822-827

8. Seoane LM, López M, Tovar S, Casanueva FF, Señarís R, Diéguez C. Agouti-related peptide, neuropeptide $\mathrm{Y}$, and somatostatin-producing neurons are targets for ghrelin actions in the rat hypothalamus. Endocrinology. 2003;144(2):544-551.

9. Mondal MS, Date Y, Yamaguchi H, et al. Identification of ghrelin and its receptor in neurons of the rat arcuate nucleus. Regul Pept. 2005; 126(1-2):55-59

10. Kamegai J, Tamura H, Shimizu T, Ishii S, Sugihara H, Wakabayashi I. Central effect of ghrelin, an endogenous growth hormone secretagogue, on hypothalamic peptide gene expression. Endocrinology. 2000;141(12):4797-4800.

11. Kamegai J, Tamura H, Shimizu T, Ishii S, Sugihara H, Wakabayashi I. Chronic central infusion of ghrelin increases hypothalamic neuropeptide $\mathrm{Y}$ and Agouti-related protein mRNA levels and body weight in rats. Diabetes. 2001;50(11):2438-2443.

12. Wang L, Saint-Pierre DH, Taché Y. Peripheral ghrelin selectively increases Fos expression in neuropeptide $\mathrm{Y}$ - synthesizing neurons in mouse hypothalamic arcuate nucleus. Neurosci Lett. 2002;325(1):47-51.

13. Wren A, Seal L, Cohen M, et al. Ghrelin enhances appetite and increases food intake in humans. J Clin Endocrinol Metab. 2001;86(12): 5992.

14. Chen CY, Fujimiya M, Laviano A, Chang FY, Lin HC, Lee SD. Modulation of ingestive behavior and gastrointestinal motility by ghrelin in diabetic animals and humans. J Chin Med Assoc. 2010;73(5):225-229.
15. Hahn TM, Breininger JF, Baskin DG, Schwartz MW. Coexpression of Agrp and NPY in fasting-activated hypothalamic neurons. Nat Neurosci. 1998;1(4):271-272.

16. Chen HY, Trumbauer ME, Chen AS, et al. Orexigenic action of peripheral ghrelin is mediated by neuropeptide $\mathrm{Y}$ and agouti-related protein. Endocrinology. 2004;145(6):2607-2612.

17. Tamura H, Kamegai J, Shimizu T, Ishii S, Sugihara H, Oikawa S. Ghrelin stimulates $\mathrm{GH}$ but not food intake in arcuate nucleus ablated rats. Endocrinology. 2002;143(9):3268-3275.

18. Keen-Rhinehart E, Bartness TJ. NPY Y1 receptor is involved in ghrelin- and fasting-induced increases in foraging, food hoarding, and food intake. Am J Physiol Regul Integr Comp Physiol. 2007;292(4): R1728-R1737.

19. Rossi M, Kim MS, Morgan DG, et al. A C-terminal fragment of Agouti-related protein increases feeding and antagonizes the effect of alpha-melanocyte stimulating hormone in vivo. Endocrinology. 1998; 139(10):4428-4431.

20. Hagan MM, Rushing PA, Pritchard LM, et al. Long-term orexigenic effects of AgRP-(83-132) involve mechanisms other than melanocortin receptor blockade. Am J Physiol Regul Integr Comp Physiol. 2000; 279(1):R47-R52.

21. Ollmann MM, Wilson BD, Yang YK, et al. Antagonism of central melanocortin receptors in vitro and in vivo by agouti-related protein. Science. 1997;278(5335):135-138.

22. Shutter JR, Graham M, Kinsey AC, Scully S, Lüthy R, Stark KL. Hypothalamic expression of ART, a novel gene related to agouti, is up-regulated in obese and diabetic mutant mice. Genes Dev. 1997; 11(5):593-602.

23. Mountjoy KG. The human melanocyte stimulating hormone receptor has evolved to become "super-sensitive" to melanocortin peptides. Mol Cell Endocrinol. 1994;102(1-2):R7-R11.

24. Tsujii S, Bray GA. Acetylation alters the feeding response to $\mathrm{MSH}$ and beta-endorphin. Brain Res Bull. 1989;23(3):165-169.

25. Zheng H, Patterson LM, Phifer CB, Berthoud HR. Brain stem melanocortinergic modulation of meal size and identification of hypothalamic POMC projections. Am J Physiol Regul Integr Comp Physiol. 2005;289(1):R247-R258.

26. Nakazato M, Murakami N, Date $Y$, et al. A role for ghrelin in the central regulation of feeding. Nature. 2001;409(6817):194-198.

27. Chen CY, Tsai CY, Lee WJ, et al. Intracerebroventricular $O-n$ octanoylated ghrelin and its splice variant-induced feeding is blocked by insulin, independent of obestatin or CRF receptor, in satiated rats. Nutrition. 2012;28(7-8):812-820.

28. Ting CH, Chi CW, Li CP, Chen CY. Differential modulation of endogenous cannabinoid $\mathrm{CB} 1$ and $\mathrm{CB} 2$ receptors in spontaneous and splice variants of ghrelin-induced food intake in conscious rats. Nutrition. 2015;31(1):230-235.

29. Chen CY, Chao Y, Chang FY, Chien EJ, Lee SD, Doong ML. Intracisternal des-acyl ghrelin inhibits food intake and non-nutrient gastric emptying in conscious rats. Int J Mol Med. 2005;16(4):695-699.

30. Chen CY, Doong ML, Chien EJ, et al. Intracerebroventricular ghrelin enhances non-nutrient semiliquid gastric emptying in fasted conscious rats. Gastroenterol J Taiwan. 2008;25(3):242-248.

31. Chen CY, Chien EJ, Chang FY, Lu CL, Luo JC, Lee SD. Impacts of peripheral obestatin on colonic motility and secretion in conscious fed rats. Peptides. 2008;29(9):1603-1608.

32. Chen CY, Doong ML, Li CP, et al. A novel simultaneous measurement method to assess the influence of intracerebroventricular obestatin on colonic motility and secretion in conscious rats. Peptides. 2010;31(6):1113-1117.

33. Huang HH, Ting CH, Syu YF, Chang SC, Chen CY. Correlation between colonic secretion and colonic motility in rats: Role of ghrelin. World $J$ Gastroenterol. 2016;22(46):10140-10147.

34. Ting CH, Chen YC, Liaw WJ, Lin HC, Chen CY. Peripheral injection of pancreatic polypeptide enhances colonic transit without eliciting anxiety or altering colonic secretion in rats. Neuropeptides. 2016;55: $67-71$ 
35. Doong ML, Lu CC, Kau MM, et al. Inhibition of gastric emptying and intestinal transit by amphetamine through a mechanism involving an increased secretion of CCK in male rats. Br J Pharmacol.1998; 124(6):1123-1130.

36. Yeh $\mathrm{C}$, Ting $\mathrm{CH}$, Doong ML, Chi CW, Lee SD, Chen CY. Intracerebroventricular urocortin 3 counteracts central acyl ghrelin-induced hyperphagic and gastroprokinetic effects via CRF receptor 2 in rats. Drug Des Devel Ther. 2016;10:3281-3290.

37. Joppa MA, Gogas KR, Foster AC, Markison S. Central infusion of the melanocortin receptor antagonist agouti-related peptide (AgRP (83-132)) prevents cachexia-related symptoms induced by radiation and colon-26 tumors in mice. Peptides. 2007;28(3):636-642.

38. Wisse BE, Frayo RS, Schwartz MW, Cummings DE. Reversal of cancer anorexia by blockade of central melanocortin receptors in rats. Endocrinology. 2001;142(8):3292-3301.

39. Guo ZF, Ren AJ, Zheng X, et al. Different responses of circulating ghrelin, obestatin levels to fasting, re-feeding and different food compositions, and their local expressions in rats. Peptides. 2008;29(7): 1247-1254.

40. Kirchner H, Gutierrez JA, Solenberg PJ, et al. GOAT links dietary lipids with the endocrine control of energy balance. Nat Med. 2009;15(7): 741-745.

41. Liu J, Prudom CE, Nass R, et al. Novel ghrelin assays provide evidence for independent regulation of ghrelin acylation and secretion in healthy young men. J Clin Endocrinol Metab. 2008;93(5):1980-1987.

42. Wren A, Small C, Ward H, et al. The novel hypothalamic peptide ghrelin stimulates food intake and growth hormone secretion. Endocrinology. 2000;141(11):4325-4328.

43. Lucas N, Legrand R, Ouelaa W, et al. Effects of rabbit anti- $\alpha-$ melanocyte-stimulating hormone $(\alpha-\mathrm{MSH})$ immunoglobulins on $\alpha$-MSH signaling related to food intake control. Neuropeptides. 2014; 48(1):21-27.

44. Levin F, Edholm T, Schmidt PT, et al. Ghrelin stimulates gastric emptying and hunger in normal-weight humans. J Clin Endocrinol Metab. 2006;91(9):3296-3302.

45. Falkén Y, Webb DL, Abraham-Nordling M, Kressner U, Hellström PM, Näslund E. Intravenous ghrelin accelerates postoperative gastric emptying and time to first bowel movement in humans. Neurogastroenterol Motil. 2013;25(6):474-480.

46. Asakawa A, Inui A, Kaga O, et al. Ghrelin is an appetite-stimulatory signal from stomach with structural resemblance to motilin. Gastroenterology. 2001;120(2):337-345.

47. Fukuda H, Mizuta Y, Isomoto H, et al. Ghrelin enhances gastric motility through direct stimulation of intrinsic neural pathways and capsaicinsensitive afferent neurones in rats. Scand J Gastroenterol. 2004;39(12): 1209-1214.

48. Fujino K, Inui A, Asakawa A, Kihara N, Fujimura M, Fujimiya M. Ghrelin induces fasted motor activity of the gastrointestinal tract in conscious fed rats. J Physiol. 2003;550(1):227-240.
49. Matsuda M, Aono M, Moriga M, Okuma M. Centrally administered neuropeptide Y (NPY) inhibits gastric emptying and intestinal transit in the rat. Dig Dis Sci. 1993;38(5):845-850.

50. Ishiguchi T, Amano T, Matsubayashi H, Tada H, Fujita M, Takahashi T. Centrally administered neuropeptide $\mathrm{Y}$ delays gastric emptying via Y2 receptors in rats. Am J Physiol Regul Integr Comp Physiol. 2001; 281(5):R1522-R1530.

51. Allen JM, Fitzpatrick ML, Yeats JC, Darcy K, Adrian TE, Bloom SR. Effects of peptide YY and neuropeptide $\mathrm{Y}$ on gastric emptying in man. Digestion. 1984;30(4):255-262.

52. Trudel L, Tomasetto C, Rio MC, et al. Ghrelin/motilin-related peptide is a potent prokinetic to reverse gastric postoperative ileus in rat. Am J Physiol Gastrointest Liver Physiol. 2002;282(6):G948-G952.

53. Sallam HS, Oliveira HM, Gan HT, Herndon DN, Chen JD. Ghrelin improves burn-induced delayed gastrointestinal transit in rats. Am J Physiol Regul Integr Comp Physiol. 2007;292(1):R253-R257.

54. Panaro BL, Tough IR, Engelstoft MS, et al. The melanocortin-4 receptor is expressed in enteroendocrine L cells and regulates the release of peptide YY and glucagon-like peptide 1 in vivo. Cell Metab. 2014; 20(6):1018-1029.

55. Savage AP, Adrian TE, Carolan G, Chatterjee VK, Bloom SR. Effects of peptide YY (PYY) on mouth to caecum intestinal transit time and on the rate of gastric emptying in healthy volunteers. Gut. 1987;28(2): $166-170$.

56. Tough IR, Forbes S, Tolhurst R, et al. Endogenous peptide YY and neuropeptide $\mathrm{Y}$ inhibit colonic ion transport, contractility and transit differentially via Y1 and Y2 receptors. Br J Pharmacol. 2011;164(2b): 471-484.

57. Tebbe JJ, Mronga S, Tebbe CG, Ortmann E, Arnold R, Schäfer MK. Ghrelin-induced stimulation of colonic propulsion is dependent on hypothalamic neuropeptide Y1- and corticotrophin-releasing factor 1 receptor activation. J Neuroendocrinol. 2005;17(9):570-576.

58. Tebbe JJ, Tebbe CG, Mronga S, Ritter M, Schäfer MK. Central neuropeptide $\mathrm{Y}$ receptors are involved in $3 \mathrm{rd}$ ventricular ghrelin induced alteration of colonic transit time in conscious fed rats. BMC Gastroenterol. 2005;5:5.

59. Maillot C, Million M, Wei JY, Gauthier A, Taché Y. Peripheral corticotropin-releasing factor and stress-stimulated colonic motor activity involve type 1 receptor in rats. Gastroenterology. 2000;119(6): $1569-1579$.

60. Nozu T, Kumei S, Takakusaki K, Ataka K, Fujimiya M, Okumura T. Central orexin-A increases colonic motility in conscious rats. Neurosci Lett. 2011;498(2):143-146.

61. Suzuki M, Narita M, Ashikawa M, et al. Changes in the melanocortin receptors in the hypothalamus of a rat model of cancer cachexia. Synapse. 2012;66(8):747-751.

62. Fujitsuka N, Asakawa A, Uezono Y, et al. Potentiation of ghrelin signaling attenuates cancer anorexia-cachexia and prolongs survival. Transl Psychiatry. 2011;1:e23.
Drug Design, Development and Therapy

\section{Publish your work in this journal}

Drug Design, Development and Therapy is an international, peerreviewed open-access journal that spans the spectrum of drug design and development through to clinical applications. Clinical outcomes, patient safety, and programs for the development and effective, safe, and sustained use of medicines are the features of the journal, which

\section{Dovepress}

has also been accepted for indexing on PubMed Central. The manuscript management system is completely online and includes a very quick and fair peer-review system, which is all easy to use. Visit http://www.dovepress.com/testimonials.php to read real quotes from published authors. 